\title{
DESIGN OF BACKUP STIFFNESS BRACKET AND INERTIAL MASS SURFACE FOR TESTING AIRCRAFT AIRBRAKE ACTUATOR
}

\author{
Bharath R K $\mathbf{K}^{\mathbf{1}}$, Sunil N K $\mathbf{2}^{\mathbf{2}}$ \\ ${ }^{I}$ Department of Mechanical Engineering, S.J.C Institute of Technology, Chickballpur, India \\ Bharathrk.rk@gmail.com \\ ${ }^{2}$ Department of Mechanical Engineering , S.J.C Institute of Technology, Chickballpur, India \\ gsgsunil@gmail.com
}

\begin{abstract}
All aircraft motion or maneuvers are regulated by control surfaces which are operated by the pilot from the cockpit. The flight control surfaces are classified into primary control surfaces and secondary control surfaces. Airbrake is a secondary control surface. For operating the airbrake, a linear hydraulic actuator is used. This airbrake actuator has to undergo Hydro Mechanical Oscillation (HMO) test with backup mounting and airbrake surface inertia similar to that of the aircraft. In order to ascertain the stability of operation of the actuators throughout the operating frequency range, HMO test will have to be carried out mandatorily for all airbrake actuators. The test setup for HMO consists of an equivalent airbrake surface along with the actuator and backup stiffness bracket as same as that of aircraft surface. In order to validate the backup stiffness bracket a known force is applied on the bracket and deflection due to this force is noted. The stiffness obtained thereafter shall be same as that of aircraft backup stiffness. Also the equivalent airbrake surface used during the test shall have the same weight, center of gravity and inertia as that of actual aircraft airbrakes. In this paper, the design of backup stiffness bracket for airbrake actuator is been detailed. The validation of design is done theoretically as well as by using CATIA V5 R21 CAD package.
\end{abstract}

Keywords: Control Surfaces, Hydro Mechanical Oscillations (HMO), Maneuvers, Leading Edge Slat (LES).

\section{INTRODUCTION}

The Aircraft control surfaces allow a pilot to adjust and control the aircraft's movements. The flight surfaces control the three main axes of the aircraft's orientation which are roll, pitch and yaw about longitudinal, lateral and vertical axis. The flight control systems on an aircraft are typically classified into two categories namely, 1) Primary control surfaces 2) Secondary control surfaces.(ref fig 1)

\subsection{Primary Control Surfaces}

Primary system in an aircraft typically control all components i.e., roll, pitch and yaw that guides an aircraft during its flight. The components of the primary control system are:

1) Ailerons.

2) Elevators.

3) Rudder.

\subsection{Aileron}

Ailerons are mounted on the trailing edge of each wing. These surfaces help in roll of the aircraft.

\subsection{Elevator:}

Elevators are placed in rear side of the horizontal stabilizer. They are used to pitch the aircraft up or down causing it to climb or dive.

\subsection{Rudder:}

Rudder is placed on the rear side of the aircraft vertical stabilizer. They help in turning the aircraft right or left, this is called yawing. [1][3]

\subsection{Secondary control surfaces.}

Secondary flight controls improve the performance characteristics of the aircraft or relieve the pilot of using excessive control force. The secondary control surfaces are Leading Edge Slat (LES), Airbrake, Spoilers, Flaps and Trim Systems.

\subsection{Leading Edge Slat (LES):}

Usage of LES surfaces generates higher lift at low air speeds thereby improving angle of attack capability of aircraft.

\subsection{Airbrake:}

The airbrake surface is the secondary control surface of the flight control system. These surfaces upon deployment reduce the speed of aircraft due to air drag. Lowering aircraft speeds is needed during air to air combat missions wherein tight maneuvers are needed to evade enemy aircraft. [3]

\subsection{Spoilers:}

A spoiler (sometimes called a lift spoiler or lift dumper) is a device intended to reduce lift in an aircraft. Spoilers are 
plates on the top surface of a wing that can be extended upward into the airflow to spoil it. By so doing, the spoiler creates a controlled stall over the portion of the wing behind it, greatly reducing the lift of that wing section. Spoilers differ from airbrakes in that airbrakes are designed to increase drag. [2][4]

\subsection{Flaps:}

Flaps are similar in functionality as that of LES but are placed at the rear side of the wing.

\subsection{Stabilizer:}

There are two types of stabilizers according to their position; there are horizontal and vertical stabilizers. The horizontal stabilizer is the main control surface of the aircraft. It functions as a wing does, creating a second point of lift along the fuselage which provides stability to the aircraft in the Z-axis.

The vertical stabilizers or fins, of aircraft, missiles or bombs are typically found on the end of the fuselage or body, and are intended to reduce aerodynamic side slip and provide directional stability. The trailing end of the stabilizer is typically movable, and called the rudder; this allows the aircraft pilot to control yaw. [5][8]

\subsection{Servo tabs:}

Some mechanical flight control systems use Servo tabs that provide aerodynamic assistance. Servo tabs are small surfaces hinged to the control surfaces. The flight control mechanisms move these tabs, aerodynamic forces in turn move, or assist the movement of the control surfaces reducing the amount of mechanical forces needed.

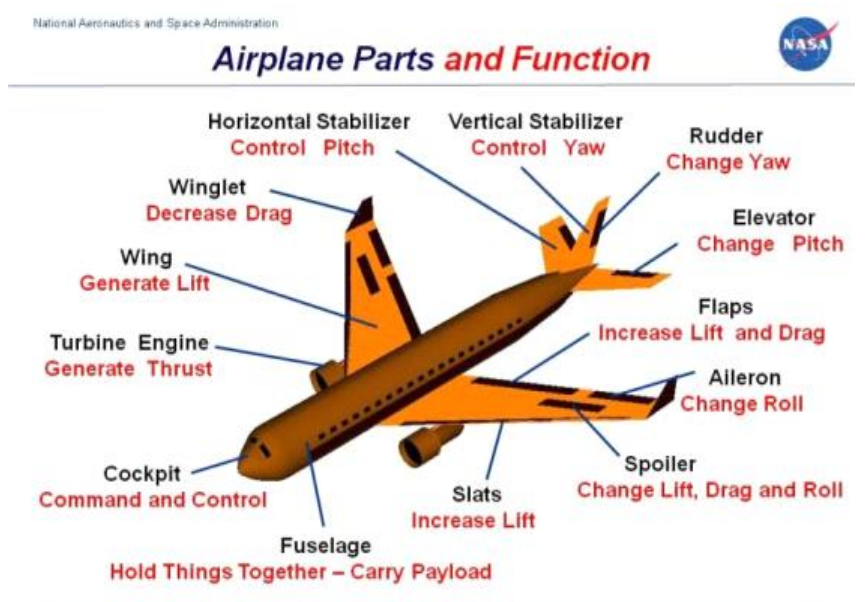

Fig 1: showing the various control surfaces in an aircraft.

[11]

\section{Results and discussion:}

In this work, the design of backup stiffness bracket for airbrake actuator for HMO testing is verified theoretically and analytically this has been discussed in the following section in detail.

\subsection{Theoretical analysis:}

The force exerted by the airbrake actuator at the tail end which is connected to the bracket which is as same as the aircraft surfaces material.

The force exerted by the airbrake actuator is maximum of 5 tons at its tail end. The backup stiffness range is $10^{8}(\mathrm{~N} / \mathrm{m})$ to $10^{9}(\mathrm{~N} / \mathrm{m})$. As the bracket is redesigned in the form of a torsion bar. The primary effect is torsion due to the torque created at the center of the bracket holding. By, considering all the known values and constants, the variation of the various other parameters are calculated, verified and the optimum value is selected. The bracket with major dimension is as shown in fig 2 .

\section{Torsional equation:}

$(\mathrm{T} / \mathrm{J})=\left(\tau_{\mathrm{S}} / \mathrm{R}\right)=((\mathrm{G} \Theta) / \mathrm{L})$

$\mathrm{T}=\mathrm{F}^{*} \mathrm{R}$

$\left[\mathrm{T}=\right.$ torque; $\tau_{\mathrm{s}}=$ shear stress;

$\mathrm{F}=50000 \mathrm{~N}$ (force); $\mathrm{R}=\mathrm{h}$ (height between the force acting and the center of the bar)] [9]

Properties of EN24 steel.

$\sigma_{\mathrm{YT}}=680 \mathrm{MPa} .($ Yield stress)

$\mathrm{G}=75 \mathrm{GPa}$.(Rigidity modulus)

$\mathrm{E}=205 \mathrm{GPa}$.(Young's modulus)

$\left(\left(\mathrm{F}^{*} \mathrm{~h}\right) /\left(\left(\mathrm{\Pi d}^{4}\right) /(32)\right)=((\mathrm{G} \Theta) / \mathrm{L})\right.$

$\Theta$ is the angular deflection.

$\mathrm{L}$ is length of the bar.

On substituting the known values.

We get,

$\mathrm{d}=1.6427(\mathrm{hL} / \Theta)^{(0.25)}$

W.K.T

Stiffness $(\mathrm{K})=($ FORCE $(\mathrm{F}) / \operatorname{Deflection}(\mathrm{y}))$

$\mathrm{K}=\mathrm{F} / \mathrm{y}=\mathrm{F} /(\mathrm{h} \Theta)$

[Because, $\mathrm{y}=\mathrm{h} \Theta]$

$\Theta=F /(K h)$ 


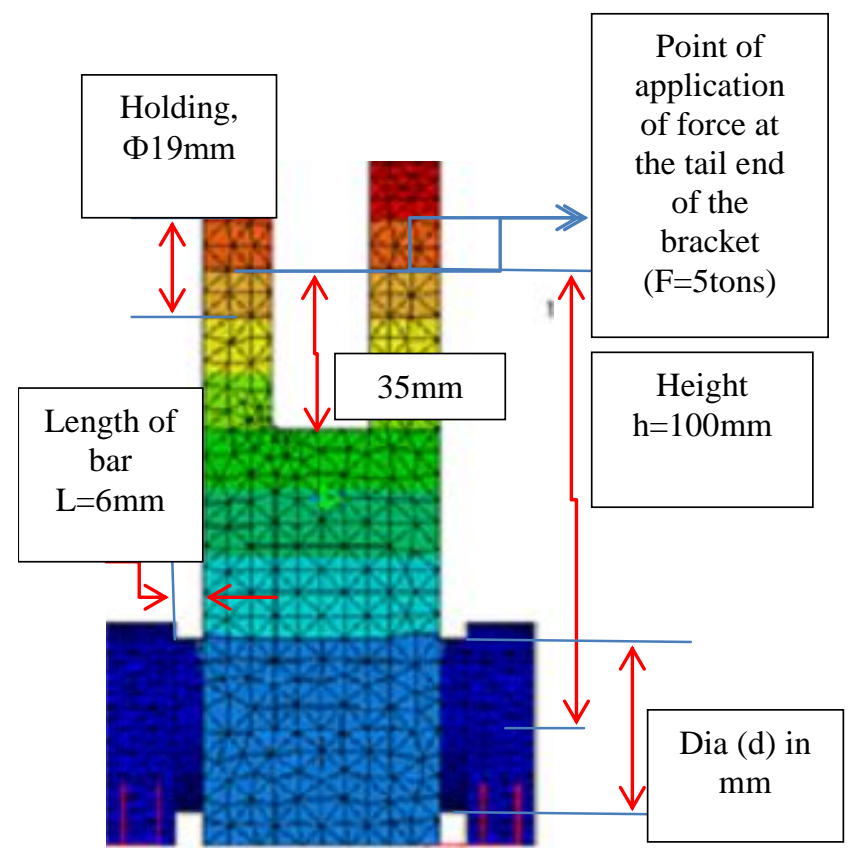

Fig 2: CATIA model showing the major dimensions of bracket.

Table1: Showing variation of diameter (d) for the variation of height (h) and deflection $(\Theta)$, for stiffness $K=10^{8} \mathrm{~N} / \mathrm{m}$ and length $(\mathrm{L}), \mathrm{L}=(2 * 6) \mathrm{mm}$.

\begin{tabular}{|c|c|c|}
\hline $\begin{array}{l}\mathrm{h} \text { in } \\
(\mathrm{mm})\end{array}$ & $\begin{array}{l}\Theta=(\mathrm{F} /(\mathrm{Kh}))= \\
(0.5 / \mathrm{h}) \\
\text { in }(\mathrm{rad}) .\end{array}$ & $\begin{array}{c}\mathrm{d}=1.61427(\mathrm{hL} / \Theta)^{\wedge}(.25) \\
(\mathrm{mm})\end{array}$ \\
\hline 80 & 0.006 & 31.957 \\
\hline 90 & 0.005 & 33.896 \\
\hline 100 & 0.005 & 35.729 \\
\hline 110 & 0.004 & 37.473 \\
\hline 120 & 0.004 & 39.139 \\
\hline 130 & 0.003 & 40.738 \\
\hline 140 & 0.003 & 42.275 \\
\hline 150 & 0.003 & 43.759 \\
\hline 160 & 0.003 & 45.194 \\
\hline 170 & 0.002 & 46.585 \\
\hline 180 & 0.002 & 47.936 \\
\hline 190 & 0.002 & 49.249 \\
\hline 200 & 0.002 & 50.529 \\
\hline
\end{tabular}

Table 2: Showing variation of diameter (d) for the variation of height (h) and deflection $(\Theta)$, for stiffness $K=10^{9} \mathrm{~N} / \mathrm{m}$ and length $(\mathrm{L}), \mathrm{L}=(2 * 6) \mathrm{mm}$

\begin{tabular}{|c|c|c|}
\hline $\begin{array}{l}\text { h } \\
\text { in } \\
(\mathrm{mm})\end{array}$ & $\begin{array}{l}\Theta=(\mathrm{F} /(\mathrm{Kh}))= \\
(0.5 / \mathrm{h}) \\
(\mathrm{rad})\end{array}$ & $\begin{array}{l}\mathrm{d}= \\
1.61427(\mathrm{hL} / \Theta)^{\wedge}(.25) \\
\text { in }(\mathrm{mm})\end{array}$ \\
\hline 80 & 0.0006 & 56.829 \\
\hline 90 & 0.0005 & 60.276 \\
\hline 100 & 0.0005 & 63.537 (selected) \\
\hline 110 & 0.0004 & 66.638 \\
\hline 120 & 0.0004 & 69.601 \\
\hline 130 & 0.0003 & 72.443 \\
\hline 140 & 0.0003 & 75.178 \\
\hline 150 & 0.0003 & 77.817 \\
\hline 160 & 0.0003 & 0.0003 \\
\hline 170 & 0.0002 & 0.0002 \\
\hline 180 & 0.0002 & 85.244 \\
\hline 190 & 0.0002 & 87.580 \\
\hline 200 & 0.0002 & 89.855 \\
\hline
\end{tabular}

It is clearly evident that for a bracket height of $100 \mathrm{~mm}$ and a torsion shaft length of $6 \mathrm{~mm}$ on either sides of bracket, shaft diameter of $35.72 \mathrm{~mm}$ and $63.53 \mathrm{~mm}$ yields a stiffness values of $10^{8} \mathrm{~N} / \mathrm{m}$ and $10^{9} \mathrm{~N} / \mathrm{m}$ respectively. These two designs will now be analyzed further for validation in CATIA CAD package.

\subsection{Analytical Method}

The bracket is designed in CATIA V5 R21 CAD package, stress levels and deflections are analyzed using structural analysis.

The diameter of the circular section was selected by giving the values of the " $\mathrm{h}$ " for which certain $\theta$ is determined and from that the diameter is obtained as shown in table 1, 2. For the stiffness value of $10^{8} \mathrm{~N} / \mathrm{m}$ the diameter obtained theoretically is $35.72 \mathrm{~mm}$ by having this value as reference we designed the bracket in software with shaft length (L) of $6 \mathrm{~mm}$, height $(\mathrm{h})$ of $100 \mathrm{~mm}$, diameter (d) of $\Phi 38 \mathrm{~mm}$ the torsional deflection at the holding is $0.5 \mathrm{~mm}$ to $0.56 \mathrm{~mm}$, (ref fig 3 ) the stiffness value obtained is $0.94 * 10^{8} \mathrm{~N} / \mathrm{m}$ which is comparison with the theoretical result. The maximum and minimum stress levels were $489.447 \mathrm{Mpa}$ and $-48.33 \mathrm{Mpa}$ (ref fig 5).

For the stiffness value of $10^{9} \mathrm{~N} / \mathrm{m}$ the diameter obtained theoretically is $63.53 \mathrm{~mm}$ by having this value as reference we designed the bracket in software with shaft length (L) of $6 \mathrm{~mm}$, height (h) of $100 \mathrm{~mm}$, diameter (d) of $\Phi 68 \mathrm{~mm}$ the torsional deflection at the holding is $0.06 \mathrm{~mm}$ and $0.07 \mathrm{~mm}$ 
(ref fig 6) the stiffness value obtained is $0.76 * 10^{9} \mathrm{~N} / \mathrm{m}$ which is comparison with the theoretical result. The maximum and minimum stress levels were $154.50 \mathrm{MPa}$ and 17.59MPa (ref fig 7).

The torsional deflection diagrams for $\mathrm{k}=10^{8} \mathrm{~N} / \mathrm{m}$ :

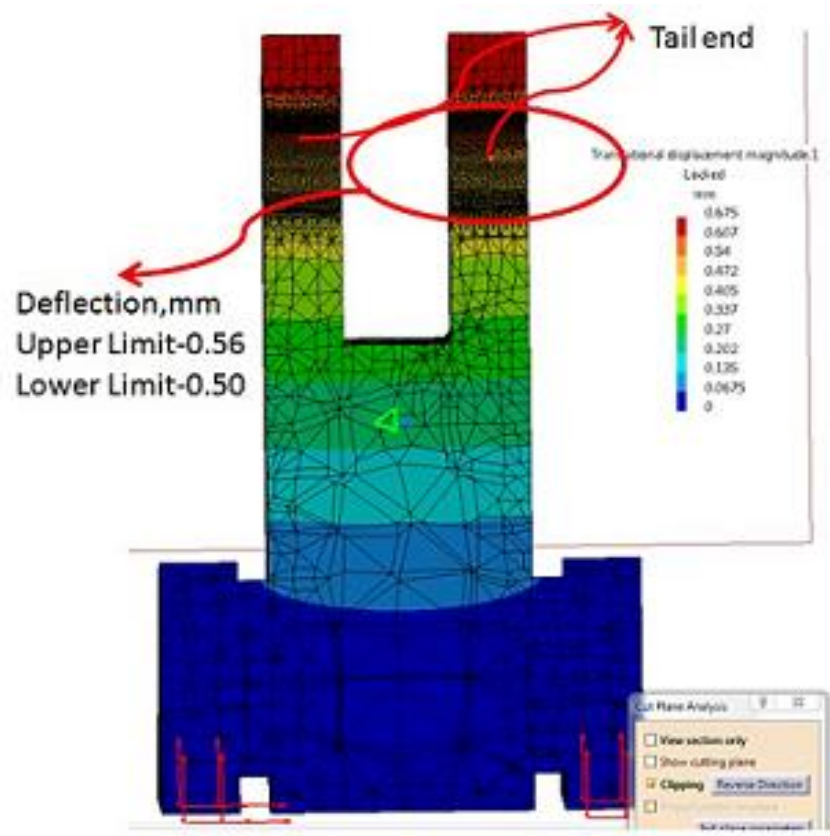

Fig 3: showing the variation of deflection at the tail end of the bracket

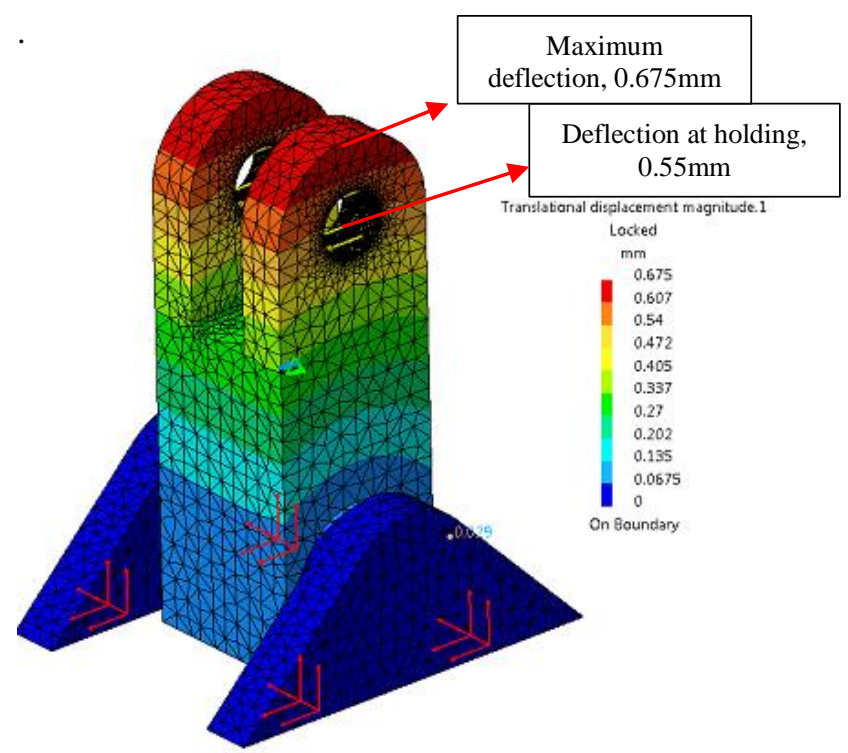

Fig 4: showing the variation of deflection at the tail end of the bracket.
The stress variation for $\mathrm{k}=10^{8} \mathrm{~N} / \mathrm{m}$ :

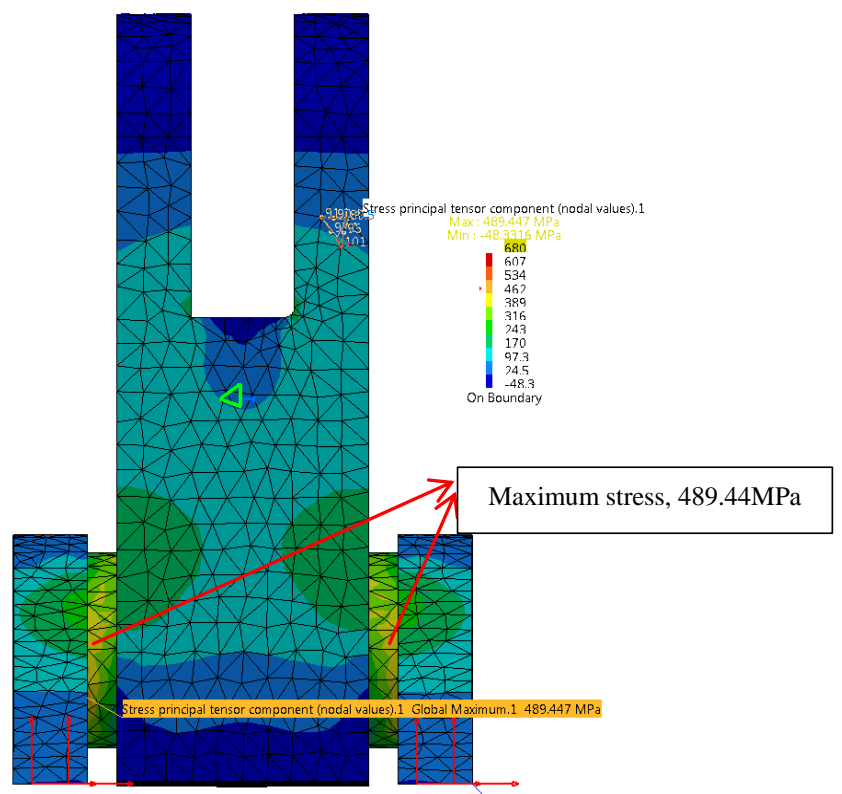

Fig 5: tetrahedron meshing, variation of principal stress is 489.44MPa and -48.33MPa.

The torsional deflection diagrams $\left(\mathrm{k}=10^{9} \mathrm{~N} / \mathrm{m}\right)$ :

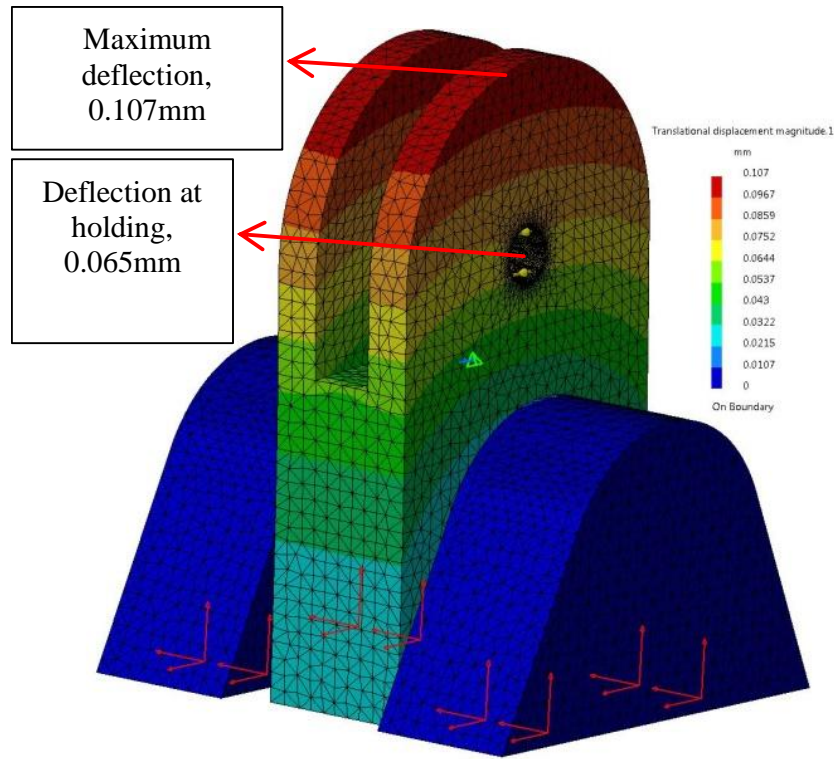

Fig 6: the max and min torsional displacement of bracket is $0.06 \mathrm{~mm}$ and $0.07 \mathrm{~mm}$. 
The stress variation $\left(\mathrm{k}=10^{9} \mathrm{~N} / \mathrm{m}\right)$ :

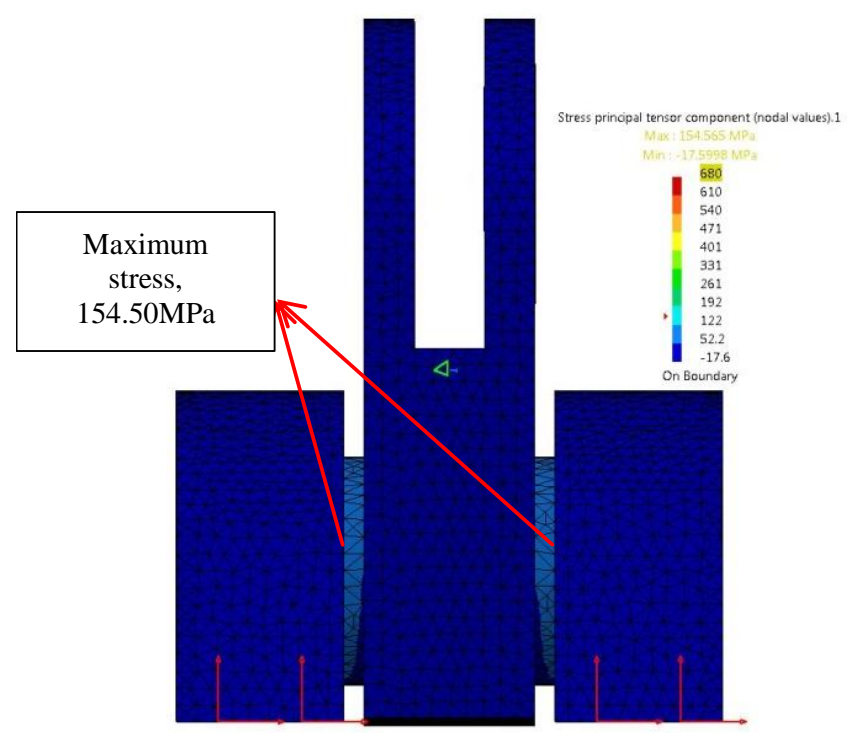

Fig 7: tetrahedron meshing, variation of principal stress is 154.50MPa and -17.59MPa.

\subsection{Inertia Surface}

Inertia surface design is based on mass distribution as in the actual condition. In centre of the plate, rectangle slot is provided for free movement of the actuator. The location of mounting of rod end side is decided by the hinge moment diagram and the distance between the mounting brackets on plate is decided by actual position of mounting bracket as in LCA surface. The actual airbrake surface is shown below.
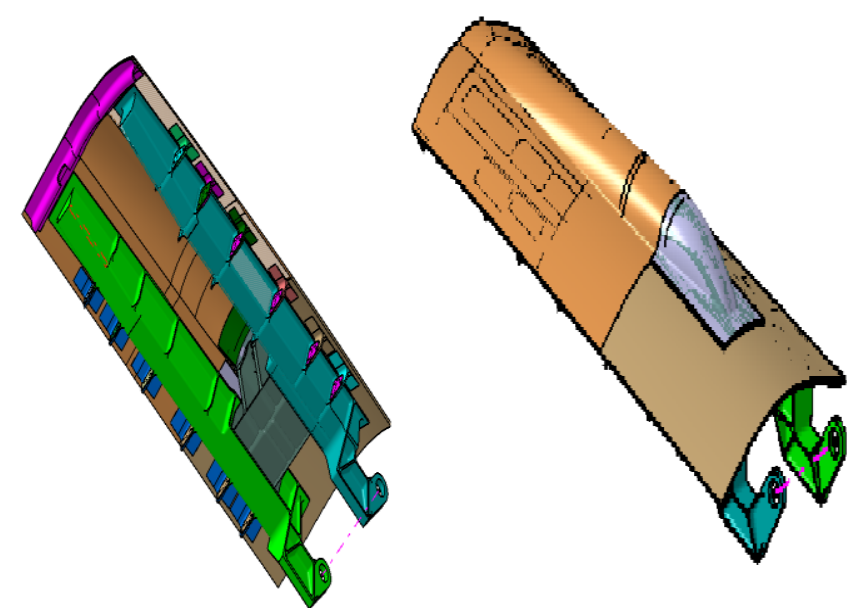

Fig 8: Airbrake Surface

The mass of plate can be changed by adding the dead weights to plate at hole provided on the top end of plate. The centre of mass can be altering by the changing the position of the mass. It can move in two direction $\mathrm{X}$ or $\mathrm{Y}$-axis.

\section{CONCLUSION}

From the analysis of the backup stiffness bracket it has been absorbed that the torsional deflection of the bracket is $0.50 \mathrm{~mm} \& 0.05 \mathrm{~mm}$ (with ref to table $1 \& 2$ ) for the stiffness values of $\mathrm{K}=10^{8} \mathrm{~N} / \mathrm{m} \& \mathrm{~K}=10^{9} \mathrm{~N} / \mathrm{m}$. The same is validated in CATIA V5 CAD package the result obtained are $0.50 \mathrm{~mm}$ to $0.56 \mathrm{~mm} \& 0.06 \mathrm{~mm}$ to $0.07 \mathrm{~mm}$ for stiffness range of $\mathrm{K}=10^{8} \mathrm{~N} / \mathrm{m}$ \& $\mathrm{K}=10^{9} \mathrm{~N} / \mathrm{m}$ at the bracket holding. The variation of principal stress acting on the member for $10^{8} \mathrm{~N} / \mathrm{m}$ stiffness is $489.44 \mathrm{MPa}(\sigma \max )$ and $-48.33 \mathrm{MPa}(\sigma$ $\mathrm{min}$ ), for $10^{9} \mathrm{~N} / \mathrm{m}$ stiffness is $154.50 \mathrm{MPa}(\sigma \max )$ and $17.59 \mathrm{MPa}(\sigma \mathrm{min})$. The airbrake surface of same weight, center of gravity and inertia is used to test the airbrake actuator for its actual operation as in an aircraft.

\section{REFERENCES}

[1]www.srmuniv.ac.in/slides/defau lt/files.

[2]www.aeronautics.nasa.gov/pdf/control surface.

[3] www.slide share.net

[4]Federal aviation administration, chapter 4 flight controls, in pilots encyclopedia of aeronautical knowledge, sky horse publishing, New York, NY pp1-4 and 2007.

[5]A C Kermode, "flight without formula"

[6]https://scribd.com/doc/45087100/flight without formulae.

[7]https://www.image of aircraft control surfaces.

[8]https://en.wikipedia.org/ wiki/flight control surfaces.

[9]Dr.K.Lingaiah \& Prof.B.R.naryana iyengar, Design Data Handbook, suma publications, volume $1,4^{\text {th }}$ edition.(fig. 2.18 an equation 2.86 ) 